\title{
Study the Efficacy of Budesonide Enema in Treating Collagenous Microscopic Colitis: An Egyptian Trial
}

\author{
Marwa Ahmed Saad Gouda ${ }^{1, *}$, Ahmed Ismail Al-Lakani', Magdy Mohammed Bedewy ${ }^{3}$ \\ ${ }^{1}$ Internal Medicine Department, Geriatric Unit, Faculty of Medicine, Alexandria University, Alexandria, Egypt \\ ${ }^{2}$ Internal Medicine Department, Gastroenterology Unit, Faculty of Medicine, Alexandria University, Alexandria, Egypt \\ ${ }^{3}$ Histo-Pathology Department, Military Academy Hospital, Alexandria, Egypt
}

Email addresses:

drmarwasaad74@gmail.com (M. A. S. Gouda), D.ahmedellakany@yahoo.com (A. I. Al-Lakani), Mgbedewy@gmail.com (M. M. Bedewy)

\section{To cite this article:}

Marwa Ahmed Saad Gouda, Ahmed Ismail Al-lakani, Magdy Mohammed Bedewy. Study the Efficacy of Budesonide Enema in Treating Collagenous Microscopic Colitis: An Egyptian Trial. American Journal of Internal Medicine. Vol. 3, No. 6, 2015, pp. $238-244$.

doi: 10.11648/j.ajim.20150306.14

\begin{abstract}
Chronic diarrhea can have a substantial impact on the patient's quality of life and overall health. Microscopic colitis (MC) is an inflammatory bowel disease, which is characterized by chronic watery diarrhea. Many drugs, including steroids, had emerged to treat MC. Our aim was testing the efficacy of Budesonide enema in improvement of patients with collagenous microscopic colitis both clinically and histo-pathologiclly. 22 patients with active microscopic colitis were enrolled in the present study, 15 women, and 7 men, with mean age of $60.9 \pm 8.5$ years. Mean duration of symptoms was $2.6 \pm 0.8$ years. Patients were given Budesonide enema $2 \mathrm{mg} / 100 \mathrm{ml}$ twice daily for 2 weeks then, once daily for 4 weeks. They were evaluated both clinically and histopathologically after 6 weeks. 18 patients $(81.8 \%)$ showed high statistically significant decrease in the thickness of collage layer, and degree of inflammation. The patients' frequency of stool decreased from 7.6 \pm 1.0 to $2.7 \pm 1.6$ motions/day $(p<0.001)$, and also consistency of stool improved $(p<0.001)$. We concluded that Budesonide enema in a dose of $2 \mathrm{mg} / 100 \mathrm{ml}$ was well tolerated and effective in induction of remission in active collagenous colitis. Effects on both clinical symptoms and inflammatory infiltrate were seen. Recurrence rate after stopping treatment is moderate. Non-responders may need prolonged duration of treatment or omitting the drugs that may be responsible for colonic inflammation.
\end{abstract}

Keywords: Chronic Diarrhea, Collagenous Colitis, Budesonide Enema

\section{Introduction}

Microscopic colitis (MC) is an inflammatory bowel disease of unknown etiology, which is characterized by chronic watery diarrhea, no macroscopic signs of large bowel involvement in the presence of specific patho-morphological changes. There are two major forms of MC, which are similar in its clinical picture, yet, heterogeneous in histological criteria: collagenous colitis (CC) and lymphocytic colitis (LC) [1].

CC was described by Lindstrom and Freeman in 1976 in a report of a patient with chronic diarrhea whose colonic biopsy specimens revealed a thickened sub-epithelial collagen layer, similar to that observed in patients with collagenous sprue [2]. In 1980, Read described microscopic colitis [3], which is clinically indistinguishable from CC but is differentiated from it by colonic biopsy features. Later, the term lymphocytic colitis (LC) was proposed by Lazenby [4], to replace the term microscopic colitis and to distinguish it from infectious colitis and inflammatory bowel disease. Population-based studies have shown that the incidence rate of microscopic colitis varies between 1 and 12 per 100,000 persons per year [5]. The overall incidence of MC appears to have increased substantially in recent years [6]. The reasons for these apparent increase in disease incidence are not clear, but increased clinical awareness, more frequent performance of diagnostic colonic biopsies, and increased use of medications that cause MC have been proposed [7]. The increased incidence has stabilized over the past years, and the incidence is associated with female gender and increasing age [8]. MC can occur in patients of any age but typically presents in late middle age and elderly. The average age at diagnosis is approximately 65 years [9]. The reason for that is unknown, and also the higher rate among women are also unknown but might be related to the higher likelihood of autoimmune diseases, hormonal alterations and/or an 
ascertainment bias as women may be more likely to seek help for intermittent watery diarrhea [10].

Identifiable risk factors for $\mathrm{MC}$ include; increasing age [11], female sex [11], autoimmune diseases such as thyroid diseases [12], and coeliac disease, past or current diagnosis of malignancy [13], and solid organ transplant [14]. MC has been associated with the use of several medications including non-steriodal anti-inflammatory drugs (NSAIDs), selective serotonin re-uptake inhibitors (SSRIs), beta-blockers, statins, biphosphonates, ticlopidine, flutamide, and proton-pump inhibitors [15].

The exact cause of microscopic colitis is unknown. Some factors are implicated as etiological factors, Genetic contribution [16], autoimmune basis [17], bile acid malabsorption [18], and gastrointestinal infection [19, 20] as Yersinia, Clostridium difficile, and Campylobacter.

Patients with MC typically present with chronic watery, non-bloody diarrhea, although a minority of patients may present with an acute onset. The precise mechanism of this diarrhea is not well understood. Factors that may play a role include bile salt induced injury, active chloride excretion, decrease in net sodium absorption, creation of a diffusion barrier by collagen band and increased local inflammatory mediators such as nitric oxide, prostaglandins, and inflammatory cytokines [10]. Associated symptoms include nocturnal bowel motions, mild abdominal pain, fatigue, slight weight loss, arthralgias, and faecal incontinence. Symptoms are often attributed to an irritable bowel syndrome [10].

The natural history of MC is variable. Many cases are selflimited, with symptoms lasting a few weeks or months. Others may be symptomatic for years in a relapsing or continuous pattern. Although a small number of case reports have suggested that MC may lead to development of ulcerative colitis, a small case series of patients with MC showed that none developed ulcerative colitis or Crohn's disease after a follow-up of at least 6 years [21]. MC also does not appear to affect colorectal cancer risk [22].

Diagnoses of microscopic colitis depends on (i) history of chronic, watery, non-bloody diarrhea, (ii) normal or near normal endoscopic and/or radiographic findings, and (iii) colonoscopy with random colonic biopsies sent for histopathological examination for findings consistent with $\mathrm{MC}$ to confirm the diagnosis.

Treatment recommendations for $\mathrm{MC}$ are based on case reports and uncontrolled studies, and give a suggested algorithm include; withdrawal of medications associated with $\mathrm{MC}$, dietary changes (avoid caffeine, lactose), trial of antidiarrheal [23], trial of budesonide, and if no improvement, diagnosis should be confirmed and other disorders should be ruled out. Prednisolone / azathioprine / mercaptopurine / methotrexate should be considered in severe MC.

Corticosteroids used in treatment of microscopic colitis decrease levels of inflammatory cytokines such as interleukin -1 , Interlenkin-6, and tumor necrosis factor through inhibition of protein synthesis and transcription [24]. Unfortunately, systemic steroids have numerous undesirable side effects as hypertension, osteoporosis, and diabetes mellitus. Budesonide is a synthetic steroid of the glucocorticoid family with a high topical anti-inflammatory activity and limited systemic availability, so many of the adverse events associated with systemic corticosteroids are diminished [25]. Budesonide is the drug which has been proved to be efficient by randomized, placebo-controlled trials, in treatment of moderate to severe microscopic colitis [9]. Budesonide therapy resulted in a significant improvement in both clinical symptoms and histological inflammatory changes, but the relapse frequency is about 61$80 \%$ [26], the relapse frequency is reduced by sustained treatment at low dosage [27].

Most studies investigated the efficacy of Budesonide tablets in treatment of $\mathrm{CC}$, and LC [28, 29]. To our knowledge, no current study investigates the efficacy of Budesonide enema in treatment of microscopic colitis.On the other hand, a lot of studies showed the efficacy of Budesonide enema in treatment of Ulcerative colitis and proctitis [30].

We hypothesized that Budesonide enema may be effective in treatment of cases of microscopic colitis as well as its effectiveness in cases of ulcerative colitis. Our aim of this study was testing the efficacy of Budesonide enema in improvement of patients with collagenous microscopic colitis both clinically and histopathologiclly.

\section{Materials and Methods}

The current study was performed in Gastroenterology Department, Faculty of Medicine- Alexandria University. The study was approved by the ethics committee of the faculty of medicine- Alexandria University. All study participants were given a detailed description of the study; its purpose and benefits, and their written informed consent was obtained.

22 Patients of both genders (15 women and 7 men), aged 45 years and older diagnosed with active microscopic colitis were included in the present study. Diagnostic criteria were histological findings of thickening of a sub-epithelial collagen layer of more than $10 \mu \mathrm{m}$. Clinical activity was defined as a daily stool frequency of $>4$. Patients with other types of bowel disease, as infectious colitis, inflammatory bowel diseases(Crohn's disease, ulcerative colitis), or ischemic colitis, celiac disease, malignancy or any severe concomitant disease, partial colonic resection, intolerance to corticosteriods, as well as pregnancy and lactation all were excluded from the study. In addition, patients treated with steriods, aminosalicylates, antibiotics, and immunesuppressants during the past 4 weeks before the study also were excluded from the study.

At baseline, thorough medical history was taken for all patients. Stool frequency and consistency were recorded at baseline and after six weeks by asking the patient for the average number of stools per day within the past 7 days and for the dominant type of stool consistency.

Colonoscopy was performed at baseline before treatment with multiple biopsies taken from transverse, descending, and sigmoid colon as well as from the rectum for histologic 
assessment. Biopsy specimens were fixed in $10 \%$ formalin and embedded in paraffin. Sections $(5-\mu \mathrm{m}$ thick) were stained with hematoxylin and eosin $(\mathrm{H} \& \mathrm{E})$, and in borderline cases, Masson trichrome stain was used. An expert pathologist assessed the thickness of collagen layer at 10 points at a magnification of 600 on a monitor screen. The inflammation in the lamina propria was assessed and graded from 0 to $3 ; 0=$ no inflammation; $1=$ mild (inflammatory infiltrate confined to the upper part of the lamina propria); $2=$ moderate (inflammatory infiltrate extending beyond the base of the crypts); and $3=$ severe (heavy inflammatory infiltrate occupying the lamina propria and infiltrating the lamina muscularis mucosa).

Patients with MC received budesonide enema (enemacort $\AA$ ) at a dose $(2 \mathrm{mg} / 100 \mathrm{~mL})$ twice daily for two weeks then once daily in the evening for 4 weeks. Clinic visits were scheduled and patients were re-evaluated after 6 weeks both clinically and histologically.

Patients were monitored for the occurrence of adverse events throughout the study. Compliance with study medication was checked by counting the medication returned at the follow-up visit.

The efficacy end point was clinical remission defined as a reduction in stool frequency less than $4 /$ day. Patients were also evaluated for the change in stool consistency.

The histologic results were examined at 6 weeks after baseline and classified as remission (reduction in the thickness of collagen layer less than $10 \mu \mathrm{m}$, plus a reduction in lamina propria inflammation), or no-response (no change in thickness of collagen layer, plus no change in lamina propria inflammation).

All patients who achieved clinical remission followed clinically for 6 weeks for recurrence of symptoms (stool frequency and consistency).According to the inclusion criteria of the clinical trial, a clinical relapse was defined as $>4$ watery or loose stools/day on average per week.

\section{Results}

22 patients diagnosed with active microscopic colitis were enrolled in the present study, 15 women $(68.2 \%)$, and 7 men $(31.8 \%)$. The range of patients 'age was $46-75$ years, with a mean of $60.9 \pm 8.5$ years. The duration of symptoms ranged from $1.5-4$ years, with a mean of $2.6 \pm 0.8$ years. At baseline, the stool frequency of the patients ranged from 6-9 motions/day, with a mean of $7.6 \pm 1.0$ motions/day. 17 patients $(77.3 \%)$ had watery diarrhea, and 5 patients $(22.7 \%)$ had soft stool diarrhea.

Patients received Budesonide enema (enemacort ${ }^{\circledR}$ ) at a dose of $2 \mathrm{mg} / 100 \mathrm{ml}$ twice daily for two weeks then once daily at night for 4 weeks. The patients were reviewed after 6 weeks for clinical improvement and prepared for colonoscopies to check histological response. 18 patients $(81.8 \%)$ showed clinical improvement as determined by decrease in stool frequency less than 4 times/ day and also improvement of stool consistency. Table 1 represents the Clinical and histological findings of the patients at baseline and after 6 weeks of treatment with Budesonide enema.

Table 1. Clinical and histological findings at baseline and after treatment.

\begin{tabular}{|c|c|c|c|c|}
\hline & & $\begin{array}{l}\text { At base } \\
\text { line }\end{array}$ & $\begin{array}{l}\text { After } \\
\text { treatment }\end{array}$ & $\mathbf{P}$ \\
\hline \multirow{2}{*}{$\begin{array}{l}\text { Stool } \\
\text { frequency }\end{array}$} & Range & $6-9$ & $1-6$ & \multirow{2}{*}{$0.001 *$} \\
\hline & Mean \pm SD & $7.6 \pm 1.0$ & $2.7 \pm 1.6$ & \\
\hline \multirow{3}{*}{$\begin{array}{l}\text { Stool } \\
\text { consistency }\end{array}$} & Watery & 17 & 0 & \multirow{3}{*}{$0.001 *$} \\
\hline & Soft & 5 & 4 & \\
\hline & Well formed & 0 & 18 & \\
\hline \multirow{12}{*}{$\begin{array}{l}\text { Thickness of } \\
\text { collagen layer } \\
\text { ( } \mathrm{m})\end{array}$} & $\mathbf{T}$ & & & \multirow{4}{*}{$0.002 *$} \\
\hline & Range & $7-20$ & $3-12$ & \\
\hline & Mean \pm SD & $12.3 \pm 2.7$ & $6.1 \pm 2.2$ & \\
\hline & D & & & \\
\hline & Range & $7-20$ & $3-10$ & \multirow[t]{2}{*}{$0.001 *$} \\
\hline & Mean \pm SD & $12.2 \pm 2.9$ & $5.8 \pm 2.5$ & \\
\hline & $\mathbf{S}$ & & & \multirow{3}{*}{$0.001 *$} \\
\hline & Range & $17-32$ & $7-14$ & \\
\hline & Mean \pm SD & $23.4 \pm 3.9$ & $8.4 \pm 2.2$ & \\
\hline & $\mathbf{R}$ & & & \multirow{3}{*}{$0.001 *$} \\
\hline & Range & $12-30$ & $6-15$ & \\
\hline & Mean \pm SD & $19.9 \pm 4.6$ & $8.1 \pm 2.4$ & \\
\hline \multirow{12}{*}{$\begin{array}{l}\text { Degree of } \\
\text { inflammation }\end{array}$} & $\mathbf{T}$ & & & \multirow{3}{*}{$0.0023 *$} \\
\hline & Range & $1-3$ & $0-2$ & \\
\hline & Mean \pm SD & $2.3 \pm 0.8$ & $0.9 \pm 0.6$ & \\
\hline & D & & & \multirow{3}{*}{$0.023^{*}$} \\
\hline & Range & $0-3$ & $0-1$ & \\
\hline & Mean \pm SD & $1.0 \pm 0.7$ & $0.2 \pm 0.4$ & \\
\hline & $\mathbf{S}$ & & & \multirow{4}{*}{$0.0041^{*}$} \\
\hline & Range & $2-3$ & $0-2$ & \\
\hline & Mean \pm SD & $2.8 \pm 0.4$ & $0.8 \pm 0.8$ & \\
\hline & $\mathbf{R}$ & & & \\
\hline & Range & $0-3$ & $0-1$ & \multirow[b]{2}{*}{$0.0054 *$} \\
\hline & Mean \pm SD & $1.3 \pm 0.9$ & $0.3 \pm 0.5$ & \\
\hline
\end{tabular}

$\mathrm{T}$ (transverse colon), D (descending colon), S (sigmoid colon), R (rectum) $\mathrm{P}$ is significant $\leq 0.005$.

Table 2 represents the correlation between clinical symptoms and its duration, the thickness of the collagen layer, and the degree of inflammation. Stool frequency and consistency were highly positively correlated with the duration of the symptoms, the thickness of the collagen layer, and the degree of inflammation.

Table 2. The Correlation between clinical symptomsand other parameters.

\begin{tabular}{lll}
\hline Stool frequency and consistency & $\mathbf{r}$ & $\mathbf{P}$ \\
\hline Duration of symptoms & 0.465 & $0.001^{*}$ \\
Degree of inflammation & & \\
T & 0.412 & $0.003^{*}$ \\
D & 0.395 & $0.014^{*}$ \\
S & 0.411 & $0.001^{*}$ \\
R & 0.398 & $0.006^{*}$ \\
Thickness of collagen layer & & \\
T & 0.416 & $0.001^{*}$ \\
D & 0.369 & $0.0165^{*}$ \\
S & 0.406 & $0.003^{*}$ \\
R & 0.368 & $0.012^{*}$ \\
\hline
\end{tabular}

$\mathrm{T}$ (transverse colon), D (descending colon), S (sigmoid colon), R (rectum) $P$ is significant $\leq 0.005$. 


\section{Discussion}

Chronic diarrhea can have a substantial impact on the patient's quality of life and overall health. A wide range of problems can cause chronic diarrhea. Up to $10 \%-20 \%$ of patients with chronic diarrhea are diagnosed with microscopic colitis (MC) [11].

The current study involved 22 patients diagnosed as active microscopic colitis, with a mean age of $60.9 \pm 8.5$ years. Gentile et al. [31], proposed that the increased incidence of $\mathrm{MC}$ with increasing age could represent a normal aging process. Another explanation for increased incidence of MC with age was given by Drossman and his colleagues [32], as young patients presented with abdominal pain or chronic diarrhea are usually diagnosed as irritable bowel syndrome and colonoscopy is avoided while in elderly patients colonoscopy is often prescribed to exclude malignancy. Thus younger people are less frequently examined by colonoscopy than older patients, which may miss the diagnosis in young adults and gives apparently increase incidence in elderly population. Also, the barrier function of the gut epithelium may be diminished in the course of a lifetime, thus by advancing age the barrier function becomes more impaired that may explain increase incidence of MC in elderly.

In our study, more than half of patients (68.2\%) were females. Estrogens and progesterone have been shown to exhibit anti-inflammatory and epithelial barrier-enhancing properties in experimentally induced colitis in rats [33]. At menopause, the fall in estrogen level may theoretically explain increase incidence of MC in middle-aged and elderly females [34].

In our study, 8 patients $(36.4 \%)$ were on regular, long-term use of non-steroidal anti-inflammatory drugs (NSAIDs) and proton pump inhibitors (PPI). 2 patients $(9.1 \%)$ were on Eltroxin for hypothyroidism, 3 patients $(13.6 \%)$ on oral hypoglycemic drugs, and another 2 patients $(9.1 \%)$ were on beta-blockers for hypertension. Many researchers found similar connections between the previously mentioned medications and MC [9, 15, 35]. Arthralgia and various autoimmune conditions as thyroid dysfunction, rheumatoid arthritis, and psoriasis often occur in patients with microscopic colitis $[11,23,26]$. In our study, 8 patients (36.4\%) had chronic arthralgia and osteoarthritis with high ESR, 2 patients $(9.1 \%)$ had hypothyroidism, and another 3 patients $(13.6 \%)$ were diabetics on oral hypoglycemic medications. Roth et al. [37], stated that the concomitant existence of many, severe diseases and the intake of several drugs may have a synergistic, harmful effect on the colonic mucosa.

Inflammatory bowel diseases (IBDs) are inflammatory conditions characterized by chronic, uncontrolled inflammation of the gastrointestinal tract [38].Crohn's disease and ulcerative colitis are the two primary types of IBD [39], while unclassified colitis (IBDU) is a form of colitis with clinical and pathological characteristics that do not meet the criteria for classification as either ulcerative colitis or Crohn's disease[40], Collagenous and lymphocytic
MC are lying under the classification; unclassified colitis [41]. Glucocorticosteroids are the standard treatment for IBDs as they result in rapid remission of disease activity [42]. New formulations of glucocorticosteroids have been developed with the aim of limiting systemic activity and reducing glucocorticosteroid adverse events. The pharmacokinetic profiles of the second-generation topical oral or rectal preparations are such that the agents have high local efficacy in the gut, but minimal systemic bioavailability due to highly efficient first-pass hepatic inactivation, thus minimizing any adverse systemic effects [43]. Most studies investigated the efficacy of budesonide tablets in induction of remission of cases of active microscopic colitis [9, 28, 29]. In contrast to $\mathrm{pH}$-modified capsules a more rapid absorption of budesonide was observed after rectal administration of budesonide enemas. The enema reaches its maximum spread within 15 minutes after administration, while budesonide peak serum concentration was not reached except after 1.5 hours after dosing. Thus the enema spreads rapidly compared to the rate of absorption of oral budesonide. According to the viscosity of the enema the distance of spread can reach up to the proximal colon. Also budesonide is absorbed without time delay after enema administration.Extensive studies investigated the efficacy of budesonide enema in management of inflammatory bowel diseases namely ulcerative colitis [44, 45]. To our knowledge, no studies investigated the efficacy of budesonide enema in microscopic colitis. Using data from enema treatment in ulcerative colitis, it was an obvious consequence to use budesonide enema in microscopic colitis patients.

In our study, multiple random measurements in well oriented biopsies were done by an experienced pathologist. Thickness of collagen layer more than $10 \mu \mathrm{m}$, and degree of inflammation of lamina propria were more pronounced in biopsies obtained from sigmoid colon, and rectum, and less pronounced in transverse and descending colon biopsies. In accordance with our findings, other studies [46], found that microscopic colitis can be diagnosed from rectal or sigmoid colon biopsies in more than $90 \%$ of cases. While, Bonderup $\mathrm{OK}$, et al. [47], detected inflammatory infiltrates were more prominent in proximal part of sigmoid colon than the rectum in more than half of their patients.

We found a positive correlation between symptoms, and the degree of inflammation as well as the thickness of collagen layer; Lee and colleagues [48], analyzed a mixed material of collagenous colitis and lymphocytic colitis and found that the intensity of clinical symptoms was unrelated to the thickness of the collagen band but a correlation between daily stool weight and inflammation in the lamina propria was found. While, in study of Bonderup OK et al. [46], the correlation between symptoms and grade of inflammation was higher, and they suggest that clinical symptoms may be more closely related to colonic inflammation than to subepithelial collagen deposition.

In our study, 18 patients $(81.8 \%)$ showed both clinical and histological improvement after 6 weeks of treatment.

Histologically, the mean thickness of collagen layer of 
colonic biopsies of transverse colon decreased from $12.3 \pm 2.7 \mu \mathrm{m}$ to $6.1 \pm 2.2 \mu \mathrm{m}(\mathrm{p}=0.002)$; in descending colon decreased from $12.2 \pm 2.9 \mu \mathrm{m}$ to $5.8 \pm 2.5 \mu \mathrm{m}(\mathrm{p}<0.001)$, in sigmoid colon decreased from $23.4 \pm 3.9 \mu \mathrm{m}$ to $8.4 \pm 2.2 \mu \mathrm{m}$ $(\mathrm{p}<0.001)$, and in the rectum decreased from $19.9 \pm 4.6 \mu \mathrm{m}$ to $8.1 \pm 2.4 \mu \mathrm{m}(\mathrm{p}<0.001)$. While in the non-responders, the mean thickness of collagen layer in transverse colon decreased from $13.5 \pm 5.44 \mu \mathrm{m}$ to $11.75 \pm 3.09 \mu \mathrm{m} \quad(\mathrm{p}=0.596)$, in descending colon decreased from $21.75 \pm 7.13 \mu \mathrm{m}$ to $19.25 \pm 3.20 \mu \mathrm{m}(\mathrm{p}=0.5460)$, in sigmoid colon decreased from $22.75 \pm 3.09 \mu \mathrm{m}$ to $20.75 \pm 0.96 \mu \mathrm{m}(\mathrm{p}=0.263)$, and in the rectum decreased from $12.75 \pm 1.26 \mu \mathrm{m}$ to $11.5 \pm 0.82 \mu \mathrm{m}$ $(\mathrm{p}=0.151)$. Improvement was more evident in the sigmoid colon and rectum.

Also, improvement of the degree of inflammation was noted in responders; with a decrease from $2.3 \pm 0.8$ to $0.9 \pm 0.6$ in transverse colon $(\mathrm{p}=0.002)$, from $1.0 \pm 0.7$ to $0.2 \pm 0.4$ in descending colon $(\mathrm{p}=0.023)$, from $2.8 \pm 0.4$ to $0.8 \pm 0.8$ in sigmoid colon ( $\mathrm{p}=0.004)$, and from $1.3 \pm 0.9$ to $0.3 \pm 0.5$ in the rectum $(\mathrm{p}=0.005)$. While, in the non-responders, the degree of inflammation decreased from $1 \pm 0.82$ to $0.5 \pm 0.58$ $(p=0.358)$ in transverse colon, from $2.5 \pm 1.0$ to $1.75 \pm 0.5$ $(p=0.228)$ in descending colon, from $2.75 \pm 0.5$ to $2.25 \pm 0.5$ $(\mathrm{p}=0.207)$, and from $1.75 \pm 0.5$ to $1.25 \pm 0.5(\mathrm{p}=0.207)$.

The patients' frequency of stool decreased from $7.6 \pm 1.0$ to $2.7 \pm 1.6$ motions/day $(p<0.001)$, and also consistency of stool improved; as 18 patients had well-formed stool $(\mathrm{p}<0.001)$.

4 patients (18.2\%) (non-responders), did not show improvement after 6 weeks of treatment neither histologically nor clinically although some improvement of stool consistency was noted. At baseline, the histological lesions of the non-responders were observed mainly in the transverse colon, and upper part of descending colon, and this may explain why those patients did not respond to treatment, as these lesions may be inaccessible by the enema. Another explanation; those patients were chronic users of NSAIDs, and they continue to use these drugs during the study, which may prevent improvement of underlying inflammation.

In a study by Stephen B et al. [49], budesonide enemas at 2.0 and $8.0 \mathrm{mg} / 100 \mathrm{~mL}$ were both clinically and statistically significantly superior to placebo in the treatment of active distal ulcerative colitis/proctitis. On the basis of this information, it seems that $2.0 \mathrm{mg} / 100 \mathrm{~mL}$ budesonide is the optimal dose for efficacy.

In our study, Follow up of patients for 6 weeks later, about $31.8 \%$ of patients had recurrence of symptoms; that their stool frequency is more than 4 times daily, plus passage of watery diarrhea according the our definition of clinical activity . Researchers showed that the remission rates of 139 patients with active ulcerative colitis at 4 weeks were $33 \%$, $51 \%$ at 8 weeks of budesonide enema usage. They concluded that Budesonide enema $2 \mathrm{mg}$ o.d. appears to be the optimal dosage in active distal UC but they could not show that budesonide enema twice weekly is sufficient to maintain remission [49].

\section{Conclusion}

We concluded that Budesonide enema in a dose of 2 $\mathrm{mg} / 100 \mathrm{ml}$ was well tolerated and effective in induction of remission in cases of active collagenous colitis. Effects on both clinical symptoms and inflammatory infiltrate were seen. Recurrence rate after stopping treatment is moderate. Non-responders may need prolonged duration of treatment or omitting the drugs that may be responsible for colonic inflammation.

\section{References}

[1] Maev IV, Kucheryavyi YA, Andreev DN, Cheremushkin SV. Evolution of ideas on microscopic colitis. Ter Arkh 2015; 87(4): 69-76.

[2] Freeman HJ, Weinstein WM, Shnitka TK, et al. Watery diarrhea syndrome associated with a lesion of the colonic basement membrane (CD)-lamina propria (LP) interface. Ann R Coll Phys Surg Can 1976; 9: 45.

[3] Read N., Krejs G., Read M., Santa Ana C., Morawski S., Fordtran J.Chronic diarrhea of unknown origin. Gastroenterology 1980; 78: 264-71.

[4] Lazenby A., Yardley J., Giardiello F., Jessurun J., Bayless T.Lymphocytic ("microscopic") colitis: a comparative histopathologic study with particular reference to collagenous colitis. Hum Path 1989; 20: 18-28.

[5] Williams, J.J., Kaplan, G.G., Makhija, S. et al. Microscopic colitis-defining incidence rates and risk factors: a populationbased study. Clin Gastroenterol Hepatol 2008; 6: 35-40.

[6] Pardi DS, Kelly CP. Microscopic Colitis .Gastroenterology 2011; 140 (4): 1155-65.

[7] Pardi, D.S., Loftus, E.V. Jr, Smyrk, T.C. et al. The epidemiology of microscopic colitis: a population based study in Olmsted County, Minnesota. Gut 2007; 56: 504-8.

[8] Harmsen W, et al. The epidemiology of microscopic colitis in Olmsted County from 2002 to 2010: a population-based study. Clin Gastroenterol Hepatol 2014; 12: 838-42.

[9] Münch A., Aust D., Bohr J., Bonderup O., Fernandez-Banares F., Hjortswang H., et al.Microscopic colitis: current status, present and future challenges: statements of the European Microscopic Colitis Group. J Crohns Colitis 2012; 6: 932-45.

[10] Jennifer J. Williams; Paul L. Beck; Christopher N. Andrews; David B. Hogan; Martin A. Storr. Microscopic Colitis - A Common Cause of Diarrhoea in Older Adults. Age Ageing 2010; 39(2): 162-8.

[11] Olesen, M., Eriksson, S., Bohr, J. et al. Microscopic colitis: a common diarrheal disease (An epidemiological study in Orebro, Sweden, 1993-1998). Gut 2004; 53: 346-50.

[12] Cindoruk M, Tuncer C, Dursun A, et al. Increased colonic intraepithelial lymphocytes in patients with Hashimoto's thyroiditis. J Clin Gastroenterol 2002; 34: 237-9.

[13] Chan JL, Tersmette AC, Offerhaus GJ, Gruber SB, Bayless TM, Giardiello FM. Cancer risk in collagenous colitis. Inflamm Bowel Dis 1999; 5: 40-3. 
[14] Kaplan GG, Seminowich S, Williams J, et al. The risk of microscopic colitis in solid-organ transplantation patients: a population-based study. Transplantation 2008; 85: 48-54.

[15] Fernandez-Banares F, Esteve M, Espinos JC, et al. Drug consumption and the risk of microscopic colitis. Am J Gastroenterol 2007; 102: 324-30.

[16] Koskela RM, Karttunen TJ, Niemela SE, Lehtola JK, Ilonen J, Karttunen RA. Human leucocyte antigen and TNFalpha polymorphism association in microscopic colitis. Eur J Gastroenterol Hepatol 2008; 20: 276-82.

[17] Cindoruk M, Tuncer C, Dursun A, et al. Increased colonic intraepithelial lymphocytes in patients with Hashimoto's thyroiditis. J Clin Gastroenterol 2002; 34: 237-9.

[18] Ung KA, Gillberg R, Kilander A, Abrahamsson H. Role of bile acids and bile acid binding agents in patients with collagenous colitis. Gut 2000; 46: 170-5.

[19] Perk G, Ackerman Z, Cohen P, Eliakim R. Lymphocytic colitis: a clue to an infectious trigger. Scand J Gastroenterol 1999; 34: 110-2.

[20] Erim T, Alazmi WM, O'Loughlin CJ, Barkin JS. Collagenous colitis associated with Clostridium difficile: a cause effect? Dig Dis Sci 2003; 48: 1374-5.

[21] Bonderup OK, Folkersen BH, Gjersoe P, Teglbjaerg PS. Collagenous colitis: a long-term follow-up study. Eur J Gastroenterol Hepatol 1999; 11: 493-5.

[22] Chan JL, Tersmette AC, Offerhaus GJ, Gruber SB, Bayless TM, Giardiello FM. Cancer risk in collagenous colitis. Inflamm Bowel Dis 1999; 5: 40-3.

[23] Bohr J, Tysk C, Eriksson S, Abrahamsson H, Jarnerot G. Collagenous colitis: a retrospective study of clinical presentation and treatment in 163 patients. Gut 1996; 39: 84651.

[24] Fine KD, Lee EL. Efficacy of open-label bismuth subsalicylate for the treatment of microscopic colitis. Gastroenterology 1998; 114: 29-36.

[25] Vikram T, Nilesh Ch. Use of Budesonide in the Treatment of Microscopic Colitis. Saudi J Gastroentrol 2010; 16(3): 236-8.

[26] Bonderup O., Hansen J., Teglbjaerg P., Christensen L., Fallingborg J.Long-term budesonide treatment of collagenous colitis: a randomised, double-blind, placebo-controlled trial. Gut 2009; 58: 68-72.

[27] Stewart M., Seow C., Storr M.Prednisolone and budesonide for short- and long-term treatment of microscopic colitis: systematic review and meta-analysis. Clin Gastroenterol Hepatol 2011; 9: 881-90.

[28] Miehlke S., Madisch A., Voss C., Morgner A., Heymer P., Kuhlisch E., et al.Long-term follow-up of collagenous colitis after induction of clinical remission with budesonide. Aliment Pharmacol Ther 2005; 22: 1115-9.

[29] Miehlke S., Madisch A., Karimi D., Wonschik S., Kuhlisch E., Beckmann R., et al. Budesonide is effective in treating lymphocytic colitis: a randomized double-blind placebocontrolled study. Gastroenterology 2009; 136: 2092-100.

[30] Gross V1, Bar-Meir S, Lavy A, Mickisch O, Tulassay Z, Pronai L, et al. International Budesonide Foam Study Group. Budesonide foam versus budesonide enema in active ulcerative proctitis and proctosigmoiditis. Aliment Pharmacol Ther. 2006; 15; 23(2): 303-12.
[31] Gentile N., Khanna S., Loftus E., Jr, Smyrk T., Tremaine W., Harmsen W, et al.The epidemiology of microscopic colitis in Olmsted County from 2002 to 2010: a population-based study. Clin Gastroenterol Hepatol 2014; 12: 838-42.

[32] Drossman D., Corazziari E., Talley N., Thompson W., Whitehead W., editors. (eds) Rome III: The Functional Gastrointestinal Disorders.2006 Third edition McLean, VA: Degnon.

[33] Karatepe O., Altiok M., Battal M., Kamali G., Kemik A., Aydin T., et al. The effect of progesterone in the prevention of the chemically induced experimental colitis in rats. Acta Cir Bras 2012; 27: 23-9.

[34] Pardi D., Kelly C.Microscopic colitis. Gastroenterology 2011; 140: 1155-65.

[35] Beaugerie L., Pardi D. Review article: drug-induced microscopic colitis - proposal for a scoring system and review of the literature. Aliment Pharmacol Ther 2005; 22: 277-84.

[36] Pardi D., Ramnath V., Loftus E., Jr, Tremaine W., Sandborn W. Lymphocytic colitis: clinical features, treatment, and outcomes. Am J Gastroenterol 2002; 97: 2829-33.

[37] Roth B., Manjer J., Ohlsson B. Microscopic colitis is associated with several concomitant diseases. DTI 2013; 7: $19-25$.

[38] Papadakis K., Targan S. Role of cytokines in the pathogenesis of inflammatory bowel disease. Ann Rev Med 2000; 51: 28998 .

[39] Hanauer S. Inflammatory bowel disease: epidemiology, pathogenesis, and therapeutic opportunities. Inflamm Bowel Dis 2006; 12(Suppl. 1): S3-S9.

[40] Burakoff R.Indeterminate colitis: clinical spectrum of disease. J Clin Gastroenterol 2004; 38: S41-S3.

[41] Fernandez-Banares, F., Salas, A., Esteve, M. et al. Collagenous and lymphocytic colitis (evaluation of clinical and histological features, response to treatment, and long-term follow-up). Am J Gastroenterol 2003; 98: 340-7.

[42] Travis S., Stange E., Lemann M., Oresland T., Chowers Y., Forbes A., et al. European evidence based consensus on the diagnosis and management of Crohn's disease: Current management. Gut 2006; 55(Suppl.): i16-i35.

[43] Girlich C., Scholmerich J. Topical delivery of steroids in inflammatory bowel disease. Curr Drug Deliv 2012; 9: 345-9.

[44] De Cassan C, Fiorino G, Danese S. Second-generation corticosteroids for the treatment of Crohn's disease and ulcerative colitis: more effective and less side effects?Dig Dis. 2012; 30(4): 368-75.

[45] Nunes T, Barreiro-de Acosta M, Marin-Jiménez I, Nos P, Sans M. Oral locally active steroids in inflammatory bowel disease. J Crohns Colitis 2013 Apr; 7(3): 183-91.

[46] Goff JS, Barnett JL, Pelke T, et al. Collagenous colitis: Histopathology and clinical course. Am J Gastroenterol 1997; 92: 57-60.

[47] Bonderup OK, Hansen JB, Fallingborg J, et al.Budesonide treatment of collagenous colitis: a randomized, double blind, placebo controlled trial with morphometric analysis. GUT 2003; 52 (2): 248-51. 
[48] Lee E, Schiller LR, Vendrell D, et al. Subepithelial collagen table thickness in colon specimens from patients with microscopic colitis and collagenous colitis. Gastroenterology 1992; 103: 1790-6.

[49] Stephen B, Malcolm R, Ronald P, Audrey J, Tore P, LarsGoran N, Karen WB, Lloyd, Jeffrey G.Budesonide Enema for the Treatment of Active, Distal UlcerativeColitis and Proctitis: A Dose-Ranging Study.Gastroenterology 1998; 115: 525-32.
[50] Lindgren, R. Löfberg, L. Bergholm, M. Hellblom, L. Carling, K.-A. Ung, R. Schiöler, P. Unge, C. Wallin, M. Ström, T. Persson \& O. B. Suhr.Effect of Budesonide Enema on Remission and Relapse Rate in Distal Ulcerative Colitis and Proctitis.Scandinavian Journal of Gastroenterology 2002, 37 (6): 705-10. 